\title{
Two Triumvirates: From Arbitrage to Speculation
}

We present two triplets that are each closely related.

Return-Risk-Liquidity: If an investor has high liquidity requirements, i. e. his money should always be available in short term, he generally has to expect a lower expected return. If, on the other hand, he wants to earn a high return, he usually also has to accept a higher risk.

Arbitrage-Hedging-Speculation: This triad characterizes the actors and strategies in the financial markets. On one hand, there is the contrast between the hedger and the speculator. The former prefers security and is prepared to pay a certain price for the protection of his assets or his transactions by leaving the risk with his contractual partner, the speculator. Without him he cannot act. The latter, in turn, is prepared to take risks, naturally with the intention of making a profit.

Nearly everybody dreams of arbitrage, i. e. generating risk-free profits without the need to use own capital by exploiting price differences for one and the same product on different markets. And because everyone dreams of it, arbitrage (virtually) does not exist, especially in our modern information society, where thousands of computer systems monitor the smallest price differences and detect arbitrage opportunities. If any are actually found, they disappear in the blink of an eye through buying and selling and the resulting price adjustment that goes with it. Therefore, many financial market models are built on the no-arbitrage condition for good reason. 